\title{
NMR Spectral Studies of Some Six-membered and Seven-membered Saturated Hetero Cyclic Compounds and Preparation of Some Seven- membered Saturated Hetero Cyclic Compounds and NMR Measurements
}

\author{
V. Krishnasamy*and S. Rosy Christy
}

Bharath University, Selaiyur, Chennai - 600 073, Tamil Nadu, India; nadippi@gmail.com, rosyma28@yahoo.in

\begin{abstract}
t[3] - Isopropyl -r[2],c[7]- diphenyl homopiperazin - 5 - one, was prepared using Schmidt reaction. Then, taking the solution of the compound in a suitable solvent, NMR measurements were taken. The chemical shifts were compared with those in $\mathrm{CDCl}_{3^{3}}$. The COSY, NOESY and ${ }^{13} \mathrm{C}-{ }^{1} \mathrm{H}$ correlation spectra had been recorded to assign the signals unambiguously. Coupling constants were calculated using DAERM method and also using the equations of Altona and Karplus for different torsional angles from 0 to $180^{\circ}$. The coupling constants, calculated by Altona's equation were less than those obtained by Karplus equation for some compounds for a particular range of torsional angles and greater for other range of torsional angles; hence, both Karplus and Altona's equations can be applied to these compounds satisfactorily.
\end{abstract}

Keywords: Ammonium Acetate, Ammonia, Anhydrous, Benzaldehyde, Crush, Drop-wise, Extract, Melting Point, Petroleum Ether, Stirring

\section{Introduction}

t[3] - Isopropyl -r[2],c[7]- diphenylhomopiperazin - 5 - one [63].

$\mathrm{t}[3]$ - Isopropyl -r[2],c[6]- diphenylpiperidin - 4-one was prepared from 4 - ethylpentan - 2 - one, benzaldehyde and ammonium acetate as in the case of $\mathrm{t}[3]$-methyl -r[2],c[6]- diphenylpiperidin - 4 - one. The compound, after recrystallisation from ethanol, melted at $123^{\circ} \mathrm{C}$ [lit. Mp. $\left.125-126^{\circ} \mathrm{C}\right]$.

Then, t[3] - Isopropyl -r[2],c[7]- diphenylhomopiperazin - 5 - one was prepared using Schmidt reaction and the procedure, followed by Rangarajan et al. ${ }^{1}$ as in the case of the corresponding methyl compound. was adopted. The compound after crystallisation from benzene - petroleum ether, melted at $188^{\circ} \mathrm{C}$. [ lit. mp. $\left.188^{\circ} \mathrm{C}\right]$.

\section{B - NMR Measurements}

Samples were prepared by dissolving about $10 \mathrm{mg}$ of the compounds in $0.5 \mathrm{ml}$ of DMSO -d6 containg 1\% TMS for recording $1 \mathrm{H}-\mathrm{NMR}$ and two dimensional NMR spectra.

Samples were prepared by dissolving about $50 \mathrm{mg}$ of the compounds in $0.5 \mathrm{ml}$ of DMSO $-\mathrm{d}_{6}$ containg $1 \%$ TMS for recording ${ }^{13} \mathrm{CH}$ NMR. The spectral parameters are given below:

1H NMR ( Plate - 3 )

13 C NMR ( Plate - 6 )

COSY ( Plate -4 )

NOESY ( Plate - 2)

HSQC ( Plate - 18)

HMBC ( Plate - 19) 


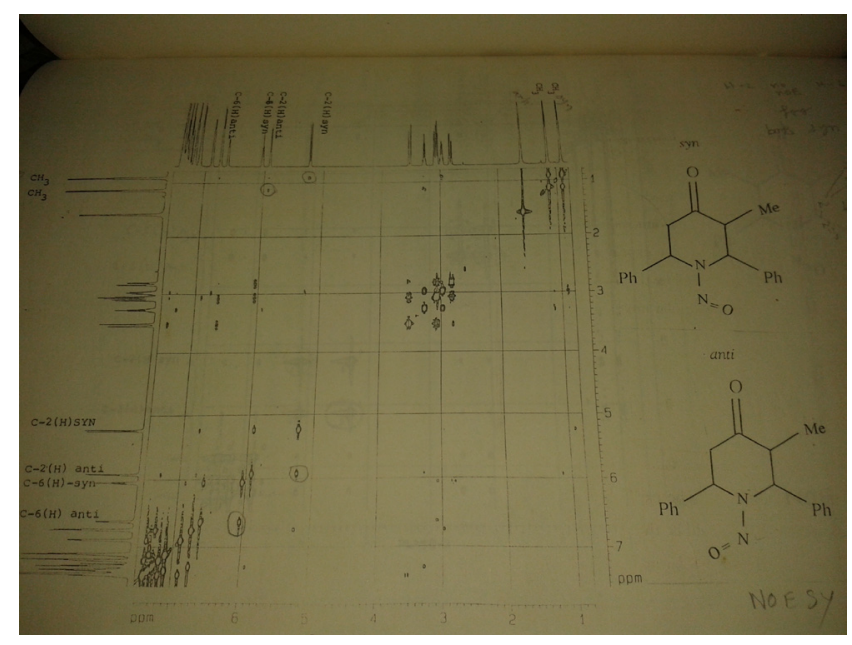

Plate - 1

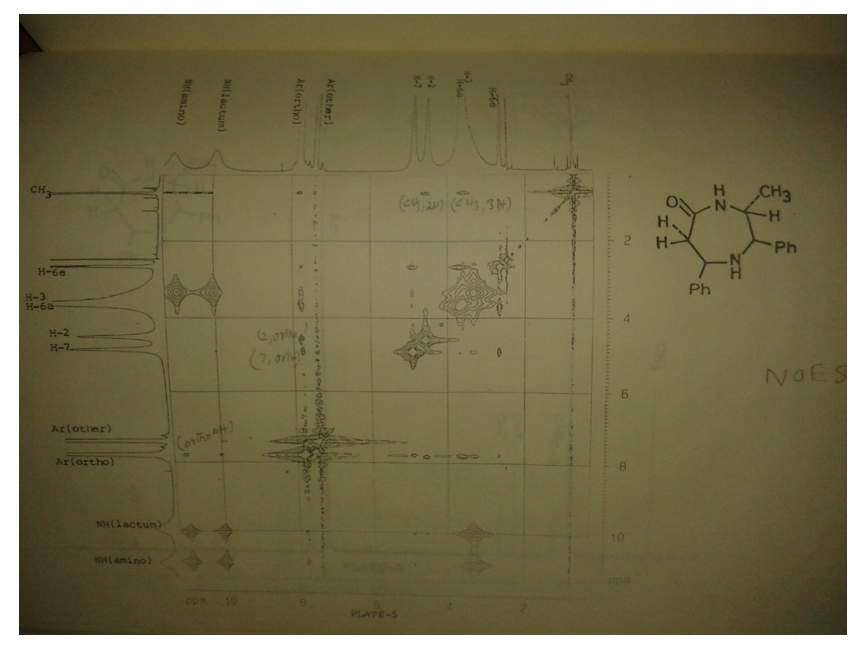

Plate - 2

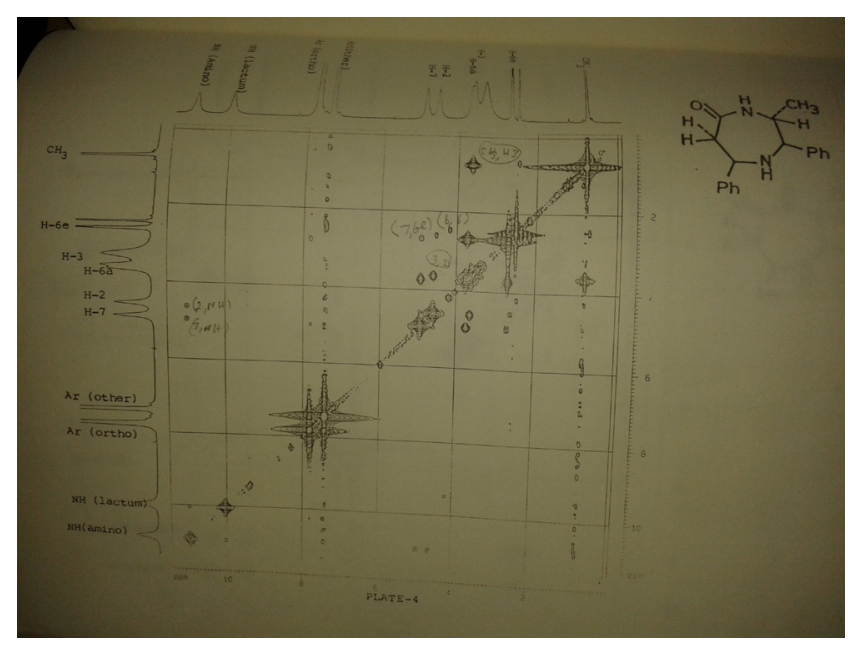

Plate - 3

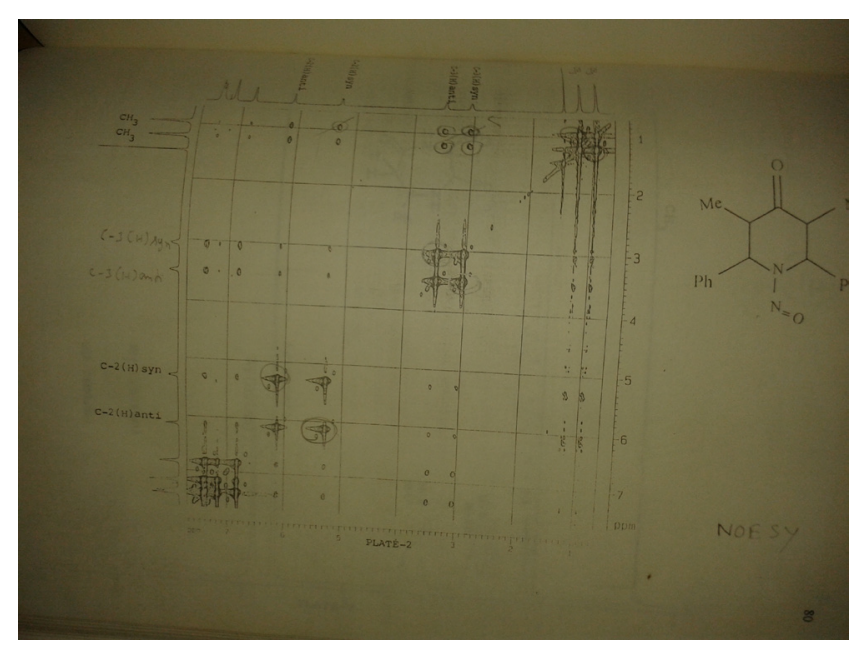

Plate -4

\section{References}

1. Rangarajan, Ramalingam T, Pandiarajan K, Chellappa J. Indian Journal of Chemistry.,vol.- 21B,p.778, year - 1982 